Meta

Journal des traducteurs

Translators' Journal

\title{
Focalized Attention on Input vs. Output during Simultaneous Interpretation: Possibly a Waste of Effort!
}

\section{Sylvie Lambert, Valeria Daró et Franco Fabbro}

Volume 40, numéro 1, mars 1995

URI : https://id.erudit.org/iderudit/003384ar

DOI : https://doi.org/10.7202/003384ar

Aller au sommaire du numéro

Éditeur(s)

Les Presses de l'Université de Montréal

ISSN

0026-0452 (imprimé)

1492-1421 (numérique)

Découvrir la revue

Citer cet article

Lambert, S., Daró, V. \& Fabbro, F. (1995). Focalized Attention on Input vs. Output during Simultaneous Interpretation: Possibly a Waste of Effort! Meta, 40(1), 39-46. https://doi.org/10.7202/003384ar
Résumé de l'article

Afin d'établir dans quelle mesure I'attention peut être focalisée soit sur le message de départ ou soit sur le message d'arrivée, 16 sujets-interprètes ont interprété des textes simples et des textes techniques sous quatre conditions: en adoptant leurs propres stratégies; en focalisant leur attention sur le message de départ; en focalisant leur attention sur le message d'arrivée; en n'interprétant qu'une voix lorsqu'ils entendent deux messages simultanés. Puisque ces conditions n'ont abouti à aucun résultat significatif, hormis une performance légèrement meilleure pour la première condition, il semblerait que pour les interprètes chevronnés, le choix d'une stratégie par rapport à une autre semble se faire inconsciemment et automatiquement. 


\title{
FOCALIZED ATTENTION ON INPUT VS. OUTPUT DURING SIMULTANEOUS INTERPRETATION: POSSIBLY A WASTE OF EFFORT!
}

\author{
Sylvie LamberT* VAleria Daró**, Franco FabBro*** \\ - Sihool of Translation and Interpretation. Universiry of Onanu. Onawa. Canado \\ * Free-lance inserpreter. Trieste, Italy \\ *** Institute of Physiology. Faculty of Medicine. Untersiry of Trieste. Trieste. Italy
}

\begin{abstract}
Résumé
Afin d'établir dans quelle mesure l'attention peut être focalisée soit sur le message de départ ou soit sur le message d'arrivée, 16 sujets-interprètes ont interprété des textes simples et des sextes techniques sous quatre conditions: en adoptant leurs propres stratégies; en focalisant lear attention sur le message de départ : en focalisant leur attention sur le message d'arrivée: en n'interprétant qu'une voix lorsqu'ils entendent deux messages simulianés. Puisque ces conditions n'ont abouti d̀ aucun résultat significatif, hormis une performance légerement meilleure pour la première condition, il semblerait que pour les interprètes che'ronnés. le choix d'une stratégie par rapport d une autre semble se faire inconsciemment ef automatiquement.
\end{abstract}

\section{INTRODUCTION}

The very essence of attention is, according to William James' simple, yet shrewd definition, the focalization and concentration of consciousness (James 1890). In particular. focalized attention is thought to be the result of the concentration of one's consciousness on a particular process (Rund 1986: Dennett 1991). Attention is considered to be a function by means of which a given performance may be improved, since it implies the involvement of the sensory systems (stimulus input), the memory systems (data processing), and the motor and vegetative systems (processed output) (see Naatanen 1992).

Simultaneous interpretation (SI) represents a typical task requiring divided attention, in that it involves several different cognitive tasks to be carried out more or less concurrently. Divided attention occurs when a subject is asked to monitor two or more tasks. such as listening to a verbal message in source language, and translating it into a target language, while simultaneously controlling his/her own output, and occasionally reading portions of a written version of the original message for clues as to the proper equivalence of specific words in the working languages. Some studies in experimental psychology revealed that after a relatively long and intense period of training, human beings can learn how to carry out several overlapping, independent tasks at the same time, such as silent reading with concurrent writing of another dictated text (Allport. Antonis and Reynolds 1972; Spelke, Hirst and Neisser 1976). The ability to divide one's attention on different synchronous tasks has been explained by three hypotheses: 1) the extra effort hypothesis, where the increased resources needed to carry out concurrent tasks require an increased effort on the part of the subject; 2) the alternation of attention hypothesis. where subjects do not carry out the different tasks in a rigorously concurrent way, but rather where they learn how to rapidly shift back and forth from the processing of one 
task to the processing of another task; 3) the auromatic montal activities hypothesis: after acquiring the ability to carry out a task involving divided attention. there is no need to monitor every single mental activity through a central processing system, since some of these activities can be carried out automatically. Following experimental investigation. these three hypotheses turned out to be equally useful in order to describe the different stages characterizing the process of acquisition of tasks implying divided attention. In the initial stages, subjects have to make an "extra effort" in order to carry out the required tasks and generally tend to alternate their attention on different aspects of the global task. whereas after having acquired the complex concurrent lasks, their effort decreases and some aspects of the tasks become automatized (Hirst. Spelke. Reaves. Caharack and Neisser $198(1)$.

As to the role of attention during SI, only a few experimental studies exist in the literature (see Gerver 1976). Lawson (1967) analyzed the ability (o) translate oral texts which were sent to one ear only (track 1 of a double-track tape recorder). while disruptive or distracting texts either in the source or in the target language were concurrently sent to the other ear (track 2). The subjects chosen for her experiment were English / Dutch bilingual non-interpreters, who turned out to be able to translate the messages of track 1 without being substantially disturbed by what they heard on track 2 . It was thus shown that subjects were capable of focalizing their attention on the input sent via track 1 and of ignoring verbal information which was concurrently sent via track 2.

Goldman-Eisler (1974; 1980) suggested that, during SI, attention should be consciously focalized on different aspects of the whole process, according to the degree of difficulty of the source language text and $t$ ) the direction of interpretation. In particular, while translating easy texts, interpreters have no need to focalize their attention either more on the input or more on their own output, whereas when dealing with difficult texts to be translated from L2 into L1, they should preferably focalize their altention on the input. and conversely on their own output when translating from L, I into L2.

The present paper describes an experiment which was conceived for the purpose of assessing the role of focalized attention during $S I$ in order to possibly answer the following questions:

1. Is it really useful to focalize attention either on the input (source language message) or on the output (interpreter $\$$ own production in the target language) during simultaneous interpretation tasks?

2. Does focalized attention affect interpretation performances depending on direction of translation and on the level of difficulty of the material?

3. Is there any difference in interpretation performances with regard to ear of input (either left or right) and does focalized attention somehow affect such possible differences?

\section{MATERIALS AND METHODS}

\section{Subjects}

Sixteen French / English bilingual professional interpreters ( 13 females and 3 males) served as subjects. All of them scored right-hand preference on the Briggs and Nebes test (1975), and their ages ranged between 30 and 82 years (average age $=43$ ). They had been working as simultaneous interpreters from a minimum of one year to a maximum of 29 years (average $=13$ years), and all were still active in this profession. French was the first language (L1) for 11 subjects, whereas the remaining 5 had English as L1: for each subject, French and English were the working languages. Since these interpreters operated in a Canadian, and therefore "bilingual" environment. they tended to work mainly into their respective mother-tongue, although they were often requested to work into their L2 as well. All subjects were either appointed by or working as frec-lance interpreters for 
Canadian governmental institutions, such as Parliamentary commissions, the Secretary of State, etc. All but five subjects knew other languages, such as Spanish, German, Dutch. Hebrew, and Arabic, although they did not use them as working languages.

\section{Texts}

The verbal material to be presented to the subjects was subdivided into "easy" and "difficult" texts. Easy texts consisted of 12 microtexts, each one made up of 5 simple sentences (main clauses), combined in a paratactic style which included only very common, everyday language words with high occurrence frequency. Each microtext represented a complete, coherent and cohesive unit ( $f$. de Beaugrande and Dressler 1981), corresponding to a short. meaningful and semantically exhaustive story. Most English "easy" texts were taken, with minor adaptations, from Hendrickx's practice book for simultaneous interpreting (Hendrickx 1971). The French "easy" texts were free translations of exercise drills from the same manual. Difficult texts consisted of 12 microtexts, each one made up of 5 longer main clauses, but each microtext always included a relative clause as well. Relative clauses tend to be more difficult to understand in that they seem to place more load on the processing system ( $c f$. Cook 1975). Moreover, since in English, relative pronouns provide a surface structure clue to comprehension processing, thus rendering comprehension easier than when optional relative pronouns are omitted (Fodor and Garrett 1967), it was decided to drop them in all English "difficult" sentences. Again, each microtext conveyed a complete, meaningful set of information, but this time the vocabulary consisted of low-frequency words and some of the technical terms taken from the French/English "What's What" (Bragonier and Fisher 198.3).

\section{PROCEDURE}

Easy and difficult texts in English and French were recorded by a French / English bilingual female speaker, at a rate of approximately 110 words per minute. They were presented to the subjects over stereophonic headphones. Each subject was asked to simultaneously translate, i.e. interpret, the English texts into French, and, vice-versa, that is the French lexts into English, thus performing a session with English as a source language and another with French as a source language. For each language, the interpretation tasks were to be carried out under four different conditions, namely 1) control condition, where subjects translated as they would nomally do: 2) focalized attention on the input, where subjects were asked to consciously focus their attention on the incoming message; 3) focalized attention on the output, where subjects were asked to consciously concentrate their attention on their production; and 4) condition with th'o voices. where subjects heard, on track 1 , the original text to be interpreted, and, at the same time, on track 2, a different, irrelevant text uttered by a male voice, and in the same language as the original text, which subjects were instructed to ignore. In each condition, subjects were presented with an "easy" and a "difficult" text, both of which were sent either binaurally or only to the left ear or only to the right ear. Sessions, conditions, and ears of input were strictly counter-balanced across subjects. The subjects' performances were recorded on a taperecorder and subsequently corrected and scored by two judges according to the number of correctly translated information units as well as to the overall number of errors.

\section{Scoring methods}

The 48 microtexts ( 24 in English and 24 in French, easy and difficult, respectively) were segmented into "items", mainly corresponding to words, i.e. to meaningful, minimal units which represent a source of mistakes during the translation process. For example, "he is" was considered to be two items, whereas "there is" corresponded to one item only. 
This kind of segmentation allowed us first and foremost to assess the amount of missing information in the interpretation process, i.e. all those items which were not reproduced in the target texts uttered by the subjects. Given the relative simplicity of both types of texts, most items had to be translated in any case and reproduced in the target language as well, if the interpreter was to serve the principle of fidelity to the original message. Items such as personal pronouns, which are syntactically obligatory in English but not in French, were not scored as missing, provided that the translation clearly and accurately revealed the acting persons or the involved objects. Under the heading missing information, the following 4 types of mistakes were grouped: errors of translation, omissions. imperfections (i.e. imprecise and/or inaccurate translation) and. finally, calques. The second category of mistakes included 8 types of so-called added mistakes. i.e. all kinds of errors which added some irregularities to the message in the target language, namely: additions, repetitions, morphosyntactic mistakes, slips of the tongue, false starts, pauses/long hesitations. wrong corrections and correct corrections (i.e. self-corrections made by the interpreter which either worsened or improved the original). (Conceming error classifications in SI. see Barik 1971; Gerver 1974). Errors were scored in terms of occurrence, according to their respective type and category, thus providing a clear-cut profile of the most vs. the least frequent mistakes occurring during simultaneous interpretation. The ratio between the total number of errors in each one of the two categories and the total number of original items yields the percentage of missed information and the percentage of added mistakes. respectively.

\section{RESULTS}

\section{Percentage of correctly translated items}

This percentage corresponds to the ratio between the number of items which were correctly reproduced by the interpreters in their own output and the number of items included in the original message. As expected, the easy texts (ET) were significantly better interpreted than the difficult ones (DT) in terms of percentage of correctly translated information units (or items): $\{\mathrm{ET}=95.28 \% ; \mathrm{DT}=8.3 .12 \% ; \mathrm{F}(1,1.5)=107.63 ; \mathrm{p}(0.0(1) 1)\}$.

As regards attention focalization, however, no significant difference emerged among the four different conditions: control condition: $90.04 \%$ : attention on the input: $89.15 \%$ : attention on the output: $89.25 \%$ : and two voices: $88.54 \%$.

The two directions of interpretation did not yield significant differences either: 1.2 to $\mathrm{LI}=89.98 \%$ and $\mathrm{L} 1 \mathrm{to} \mathrm{L} 2=88.51 \%$.

Similarly, there was no significant difference depending on ear of input, i.e. right (R) vs. left ( $L$ ) ear: $R=88.97 \%$ and $\mathrm{L}=89.40 \%$.

Overall results expressed in terms of the percentage of correctly translated items in easy and difficult texts, in the four conditions, in both directions of interpretation and for the respective ear of input are presented in Table 1.

As regards the easy texts, the interaction between Direction of interpretation and Ear of input turned out to be highly significant $\{F(1,15)=5.20 ; p(0 .(0) \mid\}$. indicating that subjects interpreted more accurately when working from $L, 1$ into $L, 2$, as long as the scource message was sent to the left ear.

\section{Total number of errors}

In this experiment, subjects made on average significantly more errors when interpreting difficult texts than when interpreting easy texts (ET=36.95 errors; DT $=140.47$ errors; $F(1,15)=166.23 ; p(0 .(x) 1\}$.

As to the effect of attention focalization on interpretation performances, measured in terms of number of errors. there were no significant differences among the four conditions: 
control condition=39.98; attention on the input $=44.22$; attention on the output $=47.11$; two voices $=46.11$.

There were no significant differences either between the two directions of interpretation. namely, $\mathrm{L} 2$ to $\mathrm{L} 1=80.05$; $\mathrm{L} 1$ to $\mathrm{L} 2=97.37$, nor between ear of input: $\mathrm{R}=90.39$ and $\mathrm{L}=87.03$.

The overall average number of errors made in easy and difficult texts, in the four conditions, in both directions of interpretation and for each ear of input, respectively, are presented in Table 2.

In the difficult texts, the interaction between direction of interpretation and ear of input was significant $\{F(1,15)=4.77 ; p 0.05\}$. This means that, on average, subjects made significantly fewer mistakes when interpreting from L2 into L1, provided they were listening to the original message with their left ear.

TABLE 1

Percentage of correctly translated items

\begin{tabular}{|c|c|}
\hline DIFFICULT TEXTS $=8.3 .12 \%$ & EASY TEXTS $=95.28 \%$ \\
\hline $\begin{array}{l}\mathrm{CC}=83.94 \% \\
\mathrm{Al}=82.57 \% \\
\mathrm{AO}=84.22 \% \\
\mathrm{TV}=81.78 \%(\text { n.s. })\end{array}$ & $\begin{array}{l}\mathrm{CC}=96.02 \% \\
\mathrm{AI}=95.73 \% \\
\mathrm{AO}=94.09 \% \\
\mathrm{TV}=95.30 \%(\text { n.s. })\end{array}$ \\
\hline \multirow[t]{3}{*}{$\begin{array}{l}\text { L2 to L1 }=84.40 \% \\
\text { L1 to L2 }=81.85 \% \text { (n.s.) } \\
\text { RE }=8.3 .20 \% \\
L E=8.3 .28 \% \text { (n.s.) }\end{array}$} & $\begin{array}{l}\text { L2 to } L 1=95.46 \% \\
L 1 \text { to } L 2=95.10 \% \text { (n.s.) } \\
R E=94.75 \% \\
L E=95.53 \% \text { (n.s.) }\end{array}$ \\
\hline & $\begin{array}{l}L 2 \text { to } L 1 \text { RE }=9.5 .80 \% \\
L 2 \text { to } L 1 L E=94.49 \%\end{array}$ \\
\hline & $\begin{array}{l}\mathrm{L1} \text { to } \mathrm{L} 2 \mathrm{RE}=93.71 \% \\
\mathrm{L1} \text { to } \mathrm{L} 2 \mathrm{LE}=96.57 \% *\end{array}$ \\
\hline
\end{tabular}

CC: control condition: $\mathrm{Al}$ : attention on the input: $\mathrm{AO}$ : attention on the output: $\mathrm{TV}$ : condition with two voices.

RE: inpur to the right ear: LE: input to the left ear.

L2 10 L1: direction of interpretation from $\mathrm{L} 2$ to $\mathrm{Ll}$ :

L. to L2: direction of interpretation from 1.1 to L2.

*: interaction between Direction of interpretation and Ear of input is significant $\{F(1,15)=5.20$ : $p$.05\}

n.s.: not significant

\section{DISCUSSION}

The general analysis of the percentage of correctly translated items and of the total number of errors made in the different conditions of our experiment leave the way open to some conclusions with respect to the basic questions asked at the start of the study.

1. According to the results, professional interpreters gain no advantage in focalizing their attention voluntarily on the input or on the output, since only in the control condition, where they were free to adopt their preferred interpretation strategies, did the subjects deliver their best performances. This result appeared to be independent of both the degree of complexity of the original texts and the direction of interpretation. 
Goldman-Eisler's (1974: 1980) suggestions of focalizing attention on the input during SI of difficult texts from $L .2$ into $L .1$, and vice-versa on the output when interpreting from $L 1$ to L.2, have therefore not been confirmed by our experimental results. Another interesting finding is that, according to our study, the process of simulaneous interpretation of one message sent to one ear only is not disrupted by the concurrent presence of another irrelevant message in the same language sent to the other ear. Lawson $\$$ (1967) results on attention and simultaneous interpretation have thus been corroborated by the present results as well.

TABLF 2

Average of the tolal number of errors for each subject

\begin{tabular}{|c|c|}
\hline DIFFICULT TFXTS $=140.47$ & EASY TEXTS $=.36 .95$ \\
\hline $\begin{array}{l}\mathrm{CC}=32.05 \\
\mathrm{Al}=36.49 \\
\mathrm{AO}=34.56 \\
\mathrm{TV}=37.37(\mathrm{n} . \mathrm{s} .)\end{array}$ & $\begin{array}{l}\mathrm{CC}=7.93 \\
\mathrm{AI}=7.7 .3 \\
\mathrm{AO}=12.55 \\
\mathrm{TV}=8.74(11.5 .)\end{array}$ \\
\hline $\begin{array}{l}L .2101 .1=6.3 .42 \\
L .110 L .2=77.05(n .6 .)\end{array}$ & $\begin{array}{l}1.2101 .1=16.6 .3 \\
1.1101 .2=20.32(\mathrm{n} .5 .)\end{array}$ \\
\hline $\begin{array}{l}\mathrm{RE}=72.23 \\
\mathrm{LE}=68.24(\mathrm{n} . \mathrm{s} .)\end{array}$ & $\begin{array}{l}\text { RE }=18.16 \\
L . E:=18.79(\mathrm{n} . \mathrm{s} .)\end{array}$ \\
\hline \multicolumn{2}{|l|}{$\begin{array}{l}\text { L.2 to L.1 RE }=3.35 .11 \\
\text { L2 to L.1 LEE }=28.31 *\end{array}$} \\
\hline $\begin{array}{l}\text { L1 10 L.2 RE }=37.12 \\
\text { L. 10 L.2 L.E }=39.9 .3\end{array}$ & \\
\hline
\end{tabular}

CC: control condition: Al: attention to the input: $A O$ : attention to the sutput: $T V$ : Iwo voices. $R E=$ input to the right ear: $I . l:=$ inpul to the left car.

1.2 lo 1.1: direction of enterpretation trom $1.210 \mathrm{I} .1$ :

l. 1 lo 1.2 : direction of interpretation from 1.1 lol 1.2 .

*: interaction be-1ween Direction of interpretatum and ear of input is significant $\{F(1.1 .5)=4.47: p .05\}$.

n.s.: not significallt

The conclusion may thus te drawn that, for professional interpreters, simultaneous interpretation consists of a complex series of different tasks, the majority of which becomes highly automatized (Hirst af al. 1980): Velmans 1991). The explicit request to consciously focalize one's attention on one of these SI tasks ( $e^{\prime}$.g. monitoring either one's own output or the input) not only does not improve the interpreter's performance. but is even detrimental to general, or more natural production. In complying, our subjects ended up making more general mistakes and translating less accurately than usual, as if they felt the burden of an additional lask to be performed along with all the others. Voluntarily focalization of attention on the input and/or on the output depending on the direction of interpretation and on the difficulty of the original message might still be of some help in some phases during the acquisition process of SI techniques, whereas apparently, it may he counterproductive for experienced interpreters.

2. One of our basic orienting yuestions concerned the possible differences between ear of input, a topic which pertains to the neuropsychology of simultaneous interpreting. It is generally accepted that, in right-handed individuals, the right ear has a certain advantage 
in the processing of verbal material as opposed to the left ear. Such right-ear advantage. which has been assessed in numerous studies, has been related to the general theory of hemispheric dominance for linguistic functions (Bryden 1982). In SI, however, a left-ear advantage for the source language input was found when the direction of interpretation was from L2 into L1. In other words, when interpreting from a second or " $B$ " language into a first, or A language, interpreters tend to perform better if they listen to the incoming message with their left ear as opposed to their right ear (Lambert 1989; Fabbro, Gran and Gran 1991). This is thought to be due to a greater involvement of the right cerebral hemisphere during SI (Fabbro, Gran, Basso and Bava 1990; Green, Schweda-Nicholson. Vaid. White and Steiner 1990). Our data are consistent with the idea that when interpreting complex material from L 2 into LI, with the source language message being conveyed to the left ear, interpreters make significantly fewer errors than when processing the original message with their right ear (see Table 2). Since such improved performance is not affected by the way attention is consciously focalized, it is reasonable to suppose that in SI, the left-ear advantage for the input has apparently nothing to do with attentive functions: more probably, it has more to do with other processes which are related to hemispheric specialization during simultaneous interpretation (Fabbro 1992; Daró 1992).

\section{REFERENCES}

ALLPORT, D. A., ANTONIS, B. and P. REYNOLDS (1972): "On the Division of Altention: A Disprox of the Single-channel Hypothesis", Quart. J. Experim. Psychol., 24, pp. 225-23.5.

BARIK. H. (1971): "A Description of Various Types of Omissions, Additions and Errors Encountered in Simultaneous Interpretation", Meta, 16. pp. 199.210.

DE BEAUGRANDE. R. A. and W. U. DRESSLER (1981): Einführung in die Textlinguistik. Tübingen, Max Niemeyer.

BRAGONIER, R. Jr. and D. FISHER (198.3): Le What's What-Le Qu'est-re que r'est, Paris, Editions Mengès/RTL.

BRIGiGS, (;. C. and R. D. NEBES (1975): "Patterns of Hand Preference in a Student Population", Cortex, 11 , Pp. 23()-2.38.

BRYDEN, M. P. (1982): Luterality, New York, Academic Press.

COOK, V. J. (1975): "Strategies in the Comprehension of Relative Clauses", Language' and Speech. 18. pp. 2(4-212.

DARÓ. V. (1992): "Neuropsychologische und neurolinguistısche Aspekte des Simultandolmetschprosesises", Bubel. 38, pp. 1.9.

DENNET. D. C. (1991): Consc iousness Exylained, Boston, Little, Brown and Company.

FABBRO, F. (1992): "Neuropsicologia dell"interpretazione simultanea", Archivio di Psicologia. Nearologia e" Psichicuria, 53, pp. $108-125$

FABBRO. F. GRAN, L.. BASSO, G. and A. BAVA (1990): "Cerebral Lateralization in Simultaneous Interpretation". Brain and Language. 39, pp. 69.89.

FABBRO. F. GRAN. L. and B. GRAN (1991): "Hemispheric Specialization for Semantic and Syntactic Components of Language in Simultaneous Interpreters", Brain and Language', 41. pp. 1-42.

FODOR. J. A. and M. GARRETT (1967): "Some Syntactic Determinants of Sentential Complexity", Porrept Pswhophvs., 2, pp. $289+296$

GERVER, D. (1974): "The Effects of Noise on the Performance of Simultaneous Interpreters: Accuracy of Performance", Acta Pswholorgica, 38. pp. 159-167.

GERVER. D. (1976): "Empirical Studies of Simultaneous Interpretation: A Review and a Model”. R. W. Brislin (Fo.). Translation. Applications and Re'searih. New York, Gardnet Press. pp. 165-207.

GOLDMAN-EISLER. F. (1972) "Segmentation of input in Simultaneous Translation". I. Prycheling. Research. 1. pp. $127-140$.

GOLDMAN-EISLER. F. (1980): "Psychological Mechanisms of Speech Production as Studied Through the Analysis of Simultaneous Translation“. B. Butterworth (Ed.). Language Production, London, Academic Press. vol. I, pp. 143-15.3.

GREEN, A., SCHWEDA-NICHOLSON, N., VAID, J., WHITE, N. and R. STEINER (1990): "Hemispheric Involvement in Shadowing vs. Interpretation: A Time-sharing Study of Simultaneous Interpreters with Matched Bilingual and Monolingual Controls", Brain and Language, 39, pp. 107-1.13.

HENDRICKX, P. V. (1971): Simulfuneous Interprefing. A Practice Book, London, Longman. 
HIRST, W., SPELKE, E. S.. REAVES, C. C., CAHARACK, G. and U. NEISSER (1980): "Dividing Altention Without Alternation of Automaticity". J. Experim. Psychol. 109, pp. 98-117.

JAMES, W. (1890): The Primciples of Psschology. New York. Holt.

LAMBERT, S. (1989): "Simultaneous Interpreters: One Far may be Better than Two", The Interpreters" Newsletrer. 2. pp. 11-16.

LAWSON. E. A. (1967): "Altention and Simultaneous Translation", Lunguage and Specch, 10. pp. 29-35.

NAATANEN, R. (1992): Attention and Bran Function. Hillsdale. N. J., Lawrence Erlbaum Associates.

RUND. R. R. (1986): "Verbal Hallucinations and Information Processing", Behovireral and Brain Sriences, 9. pp. $5.31-5.32$.

SPELKE. E., HIRST, W. and U. NEISSER (1976): "Skills of Divided Attention", Cognision, 4, pp. 21.5-230.

VELMANS. M. (199)]): "Is Human Information Processing Conscious?", Behavioral and Bram Sciences, 14, pp. $651-669$. 